\title{
Sampling bees in tropical forests and agroecosystems: a review
}

\author{
Sara G. Prado ${ }^{1}$ Hien T. Ngo ${ }^{2}$ Jaime A. Florez ${ }^{3}$ Jaime A. Collazo ${ }^{1,4}$
}

Received: 14 January 2017 / Accepted: 12 August 2017 / Published online: 22 August 2017

(C) The Author(s) 2017. This article is an open access publication

\begin{abstract}
Bees are the predominant pollinating taxa, providing a critical ecosystem service upon which many angiosperms rely for successful reproduction. Available data suggests that bee populations worldwide are declining, but scarce data in tropical regions precludes assessing their status and distribution, impact on ecological services, and response to management actions. Herein, we reviewed $>150$ papers that used six common sampling methods (pan traps, baits, Malaise traps, sweep nets, timed observations and aspirators) to better understand their strengths and weaknesses, and help guide method selection to meet research objectives and development of multi-species monitoring approaches. Several studies evaluated the effectiveness of sweep nets, pan traps, and malaise traps, but only one evaluated timed observations, and none evaluated aspirators. Only five studies compared two or more of the remaining four sampling methods to each other. There was little consensus regarding which method would be most reliable for sampling multiple species. However, we recommend that if the objective of the study is to estimate abundance or species richness, malaise traps, pan traps and sweep nets are the
\end{abstract}

Sara G. Prado

sprado@ncsu.edu

1 North Carolina Cooperative Fish and Wildlife Research Unit, Department of Applied Ecology, North Carolina State University, Raleigh, NC 27695, USA

2 Intergovernmental Science-Policy Platform on Biodiversity and Ecosystem Services, UN Campus, Platz der Vereinten Nationen 1, Bonn, Germany

3 Department of Biology \& Ecology Center, Utah State University, Logan, UT 84322, USA

4 U.S. Geological Survey, North Carolina Cooperative Fish and Wildlife Research Unit, Department of Applied Ecology, North Carolina State University, Raleigh, NC 27695, USA most effective sampling protocols in open tropical systems; conversely, malaise traps, nets and baits may be the most effective in forests. Declining bee populations emphasize the critical need in method standardization and reporting precision. Moreover, we recommend reporting a catchability coefficient, a measure of the interaction between the resource (bee) abundance and catching effort. Melittologists could also consider existing methods, such as occupancy models, to quantify changes in distribution and abundance after modeling heterogeneity in trapping probability, and consider the possibility of developing monitoring frameworks that draw from multiple sources of data.

Keywords Tropics · Bees · Sampling · Diversity · Abundance $\cdot$ Richness

\section{Introduction}

Tropical forests appear in over half of the world's biodiversity hotpots (Myers et al. 2000). Because wind pollination is rare in the tropics (Bawa and Crisp 1980), it is estimated that $98-99 \%$ of tropical plant species are animal pollinated (Bawa 1990), with bees being the main providers of this service (Renner and Feil 1993; Michener 2007). Yet, of the estimated 20,000 bee species in the world (Michener 2007), fewer species are found in the tropics than at higher latitudes (Michener 1979). This disparity places a premium on information about their conservation status, distribution, and responses to land use changes (e.g., agriculture) and conservations actions. Additionally, though there have been numerous observations of declines in bee species worldwide, the status of many species in the tropics remain virtually unknown (Ghazoul 2005; LeBuhn et al. 2013). 
Few studies have been designed to survey bees in tropical forests. This paucity is likely due to the difficulties involved in sampling bees in dense tropical forests (Bawa 1990). The majority of bee surveys in tropical forests and agroforests are conducted in the understory, employing pan traps (Aizen and Feinsinger 1994; Brosi et al. 2009; Gonçalves and Oliveira 2013) and timed visual observations (Klein et al. 2002, 2003a, b, c; Vergara and Badano 2009). Such sampling techniques, although cost effective, can be highly selective or biased towards certain taxa or bee size (Cane et al. 2000; Droege et al. 2010). Further, bee species are unevenly distributed within the forest, with medium to large-sized bee species foraging primarily in the canopy, and smaller bee species in the subcanopy trees (Bawa 1990). Given the vast differences in sampling methods and areas surveyed in tropical forests, it is clear that survey data can be highly skewed towards a subset of species.

Herein, we assess and summarize the state of knowledge of six commonly used sampling methods (pan traps, baits, Malaise traps, sweep nets, timed observations and aspirators; Fig. 1), and in doing so, identify the strengths and weaknesses of each method for sampling bees in tropical forests and agroforestry systems. We hope this review increases attention to the need to carefully evaluate the utility, accuracy, and precision of methods in different tropical settings, and seek consensus on standardized methods and metrics that allow comparisons across space and time. Only with such standards in place will the research community be able to monitor with confidence the status of pollinating insects in the habitats where their services are most essential.

\section{Methods}

ISI Web of Knowledge and Google scholar databases were searched between September 2014 and May 2015 using the names of each sampling method, with and without the term "tropic*". We used the literature cited within the articles, which were primarily in peer-reviewed journals, to locate other relevant articles. All papers that included assessments of the sampling method's efficacy in the tropics were included in this review. Papers which could shed light on the strengths and weaknesses of each sampling method were also included, even if they were not related to tropical research.

Using information acquired from the literature, we then summarized our findings into three tables. The first is meant to inform researchers on the various factors to be taken into account when selecting a particular sampling method (e.g. cost, processing time, usefulness for

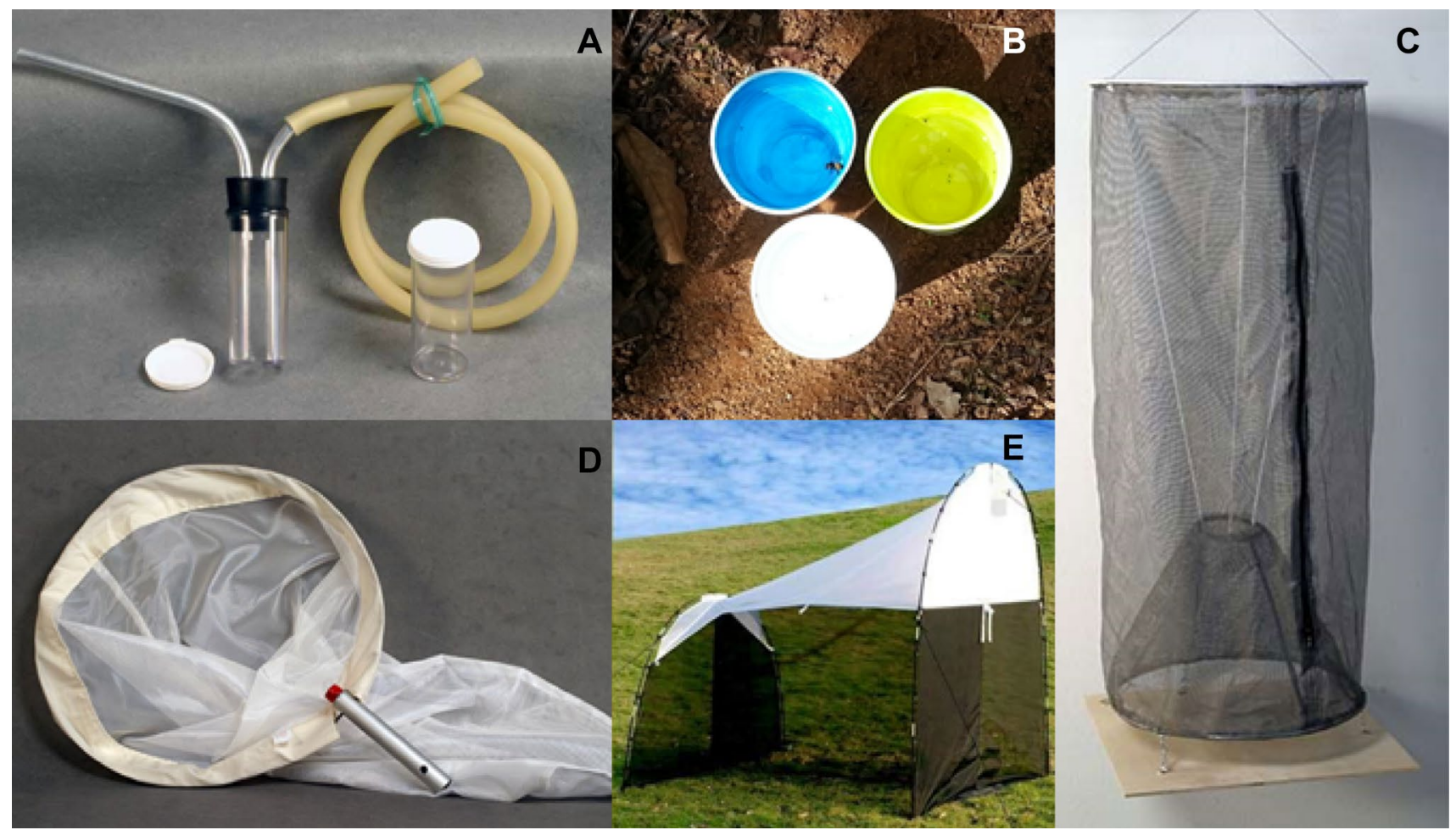

Fig. 1 Images for five of the reviewed sampling methods. a Aspirator/Pooter (product image from bioquip.com), b pan traps, c Van Someren trap (product image from bioquip.com), $\mathbf{d}$ collapsible sweep net (product image from bioquip.com), e Malaise trap (product image from bioquip.com) 
behavioral studies; Table 1). The second provides recommendations of which sampling method to use based on specific research topics (e.g. behavioral studies, species specific surveys, species richness) and habitat types surveyed (e.g. tropical agroecosystem, tropical shrubland; Table 2). The third summarizes the findings of five studies, which compared three or more sampling methods in tropical forests or agroecosystems (Table 3).

We used the terms "efficiency", "effective" and "effectiveness" to describe the method's ability to collect data on the desired variable. For example, a sampling method is effective at collecting bees if it collects one or more individual bees. In this paper, the term "effective" is used as an adjective and "effectiveness" as a noun, both referring to the same concept. We use "efficiency" to describe how effective a method is, and can be thought of as similar to 'capture per unit effort'. For example, a sampling method is efficient if it takes little time or energy to capture a certain quantity or diversity of bees.

\section{Results}

\section{Pan traps/Bowl traps/Bee bowls/Moericke traps}

Pan traps (Fig. 1b), also known as Moericke traps and bee bowls (Schauff 1986; Cane et al. 2000; Droege et al. 2010), are used to capture bees in colored receptacles that mimic the color of flowering plants, which attract and visually lure bees into the trap (Leong and Thorp 1999; Campbell and Hanula 2007). These pan traps are filled with water or propylene glycol and a small amount of surfactant (usually unscented soap) which reduces the liquid's surface tension causing insects to drown upon contact (Schauff 1986). At the end of the sampling period, drowned bees are recovered, preserved, and identified.

\section{Advantages}

Pan traps are a cost-effective (Droege 2015), passive sampling technique that can be implemented by anyone (Cane et al. 2000; Westphal et al. 2008). Pan traps are easy to set up and can be left alone once placed, reducing the amount of person-hours spent, and allowing investigators to survey more sites (Cane et al. 2000). Although there is a bias towards trapping smaller bee species (Baum and Wallen 2011; Gonçalves and Oliveira 2013), knowing that particular species may be more attracted to pan traps may allow directed sampling (Bashir et al. 2013). Another occasion where this bias may be advantageous is when researchers are trying to capture a specific group or small bees, as opposed to evaluate the overall bee diversity in an area. For example, Leong and Thorp (1999) found that pan traps are well suited for testing the presence of particular bee species in the community, including many parasitic bee species, which are rarely caught on flowers. Similar observations were made in southern Brazil, where species of Halictinae were most commonly collected, of which a single species (Augochlorella ephyra Schrottky) accounted for more than half of the collection (Gonçalves and Oliveira 2013).

Pan traps can be a valuable tool when there are few host plants to sample, as bee species richness and abundance sampled by pan traps are inversely related to flowering intensity and flowering species richness (Popic et al. 2013). Even so, in densely vegetated areas where other sampling methods may be difficult to implement, pan traps may be elevated to flower height (Cane et al. 2000; Tuell and Isaacs 2009). Furthermore, in temperate regions, studies have shown that when pan traps are elevated into the canopy, the abundance of bees captured can be greater than those placed at ground level (Tuell and Isaacs 2009; but see Bąk-Badowska 2012). Elevating pan traps can also allow an assessment of vertical distribution of insects in different habitats (Bąk-Badowska 2012). To our knowledge, the method involving elevating bowls into the canopy has yet to be carried out in the tropics.

Table 1 List of budgetary factors influencing the selection of a particular sampling technique

\begin{tabular}{|c|c|c|c|c|c|c|c|c|}
\hline Method & Passive & Active & $\begin{array}{l}\text { Collector experi- } \\
\text { ence required }\end{array}$ & Cost & Survey time & Processing time & Trap selectivity & $\begin{array}{l}\text { Vulnerability to } \\
\text { climatic vari- } \\
\text { ability }\end{array}$ \\
\hline Pan trap & $X$ & & Low & Low & Med & Variable & Med & Med \\
\hline Bait & $\mathrm{X}$ & $\mathrm{X}$ & Low & Med & High & Low & High & High \\
\hline Malaise trap & $\mathrm{X}$ & & Med & High & Low & High & Low & Low \\
\hline Sweep net & & $\mathrm{X}$ & High & Low & Variable & Low & Low-Med & High \\
\hline Timed observation & & $\mathrm{X}$ & High & Low & High & NA & Med-High & High \\
\hline Aspirator & & $X$ & High & Low & High & Low & Med-High & High \\
\hline
\end{tabular}

Herein, "trap selectivity" is defined as the bias of a sampling method leading to the misrepresentation of taxa, sizes or life stages, in samples relative to actual occurrence (Zale et al. 2013) 
Table 2 Sampling method recommendations based on research question and habitat type

\begin{tabular}{|c|c|c|c|}
\hline Habitat type & Research objective & Sampling method & References \\
\hline \multirow[t]{5}{*}{ Tropical pasture } & Species specific & $\begin{array}{l}\text { Pan traps (small bees- including Halictinae } \\
\text { and parasitic bees) }\end{array}$ & $\begin{array}{l}\text { Baum and Wallen (2011), Gonçalves and } \\
\text { Oliveira (2013) }\end{array}$ \\
\hline & Species richness & Sweep net & Smith-Pardo and Gonzalez (2007) \\
\hline & Species abundance & Sweep net and Van Somer bait trap & Smith-Pardo and Gonzalez (2007) \\
\hline & Rare species & Not found & Not found \\
\hline & Behavioral studies & Timed observations & $\begin{array}{l}\text { Florez et al. (2002), Cane (2001), Ricketts } \\
\text { (2004), Price et al. (2005), Lemaitre et al. } \\
\text { (2014), Rocha-Filho et al. (2012), Leonhardt } \\
\text { et al. (2011) }\end{array}$ \\
\hline \multirow[t]{5}{*}{ Tropical shrubland } & Species specific & Not found & Not found \\
\hline & Species richness & Not found & Not found \\
\hline & Species abundance & Sweep net & $\begin{array}{l}\text { Smith-Pardo and Gonzalez (2007), Smith-Pardo } \\
\text { (1999) }\end{array}$ \\
\hline & Rare species & Not found & Not found \\
\hline & Behavioral studies & Timed observations & $\begin{array}{l}\text { Florez et al. (2002), Cane (2001), Ricketts } \\
\text { (2004), Price et al. (2005), Lemaitre et al. } \\
\text { (2014), Rocha-Filho et al. (2012), Leonhardt } \\
\text { et al. (2011) }\end{array}$ \\
\hline \multirow[t]{5}{*}{$\begin{array}{l}\text { Secondary and mature } \\
\text { tropical forest }\end{array}$} & Species specific & $\begin{array}{l}\text { Baits (euglossine, meliponine and nocturnal } \\
\text { bees) }\end{array}$ & $\begin{array}{l}\text { Knoll and Santos (2012), Nemésio and Silveira } \\
\text { (2006), Pearson and Dressler (2009), Nemésio } \\
\text { and Morato (2006), Ramírez et al. (2010), } \\
\text { Melo et al. (2009), Janzen et al. (1982), } \\
\text { Tonhasca et al. (2003), Breed et al. (1999), } \\
\text { Carvalho et al. (2012a, b) }\end{array}$ \\
\hline & Species richness & Bait and Sweep net & Smith-Pardo (1999) \\
\hline & Species abundance & Sweep net and Malaise trap & $\begin{array}{l}\text { Smith-Pardo and Gonzalez (2007), Gonçalves } \\
\text { et al. (2012) }\end{array}$ \\
\hline & Rare species & Malaise trap & Smith-Pardo and Gonzalez (2007) \\
\hline & Behavioral studies & Baits, visual observations (video recordings) & $\begin{array}{l}\text { Breed et al. (2002), Rodríguez-Oseguera et al. } \\
\text { (2013) }\end{array}$ \\
\hline \multirow[t]{5}{*}{ Tropical agroecosystem } & Species specific & Malaise trap & Nardone (2013), Ngo et al. (2013) \\
\hline & Species richness & Sweep net & Pannure and Chandrashekara (2013) \\
\hline & Species abundance & Pan traps and aspirators (mark-recapture) & $\begin{array}{l}\text { Pannure and Chandrashekara (2013), South- } \\
\text { wood and Henderson (2000), Roubik et al. } \\
\text { (1983) }\end{array}$ \\
\hline & Rare species & Timed observations & Ricketts (2004) \\
\hline & Behavioral studies & Timed observations, aspirators and sweep net & $\begin{array}{l}\text { Florez et al. (2002), Cane (2001), Ricketts } \\
\text { (2004), Price et al. (2005), Lemaitre et al. } \\
\text { (2014), Rocha-Filho et al. (2012), Leonhardt } \\
\text { et al. (2011), Klein et al. (2003a, b, c), Nieh } \\
\text { et al. (2003a, b) }\end{array}$ \\
\hline
\end{tabular}

Pan traps also have the advantage of being easily modified for long-term sampling (Samnegård et al. 2011; Packer 2013). Replacing the soapy water solution with a propylene glycol solution (50 propylene glycol:50 water or entirely propylene glycol) reduces the amount of evaporation that takes place, as well as acts as a preservative, therefore allowing traps to remain out for weeks at a time (Thomas 2008; Packer 2013). Adding a small amount of formalin can reduce the solutions attractiveness to vertebrates, and a bit of unscented soap can help reduce the surface tension (Droege 2015). In addition to providing data on a longer time-scale, this can be beneficial when man-power is limited and frequent visits to survey sites are difficult. Using a larger bowl/ cup with more solution can also extend the amount of time the pan traps can be left out.

\section{Disadvantages}

A disadvantage of pan traps is that captures are biased towards small insects (Roulston et al. 2007; Minckley 2008; Souza and Campos 2008), and larger bees like Bombus, Centris, Svastra, Melissodes, Megachile, and Apis are 


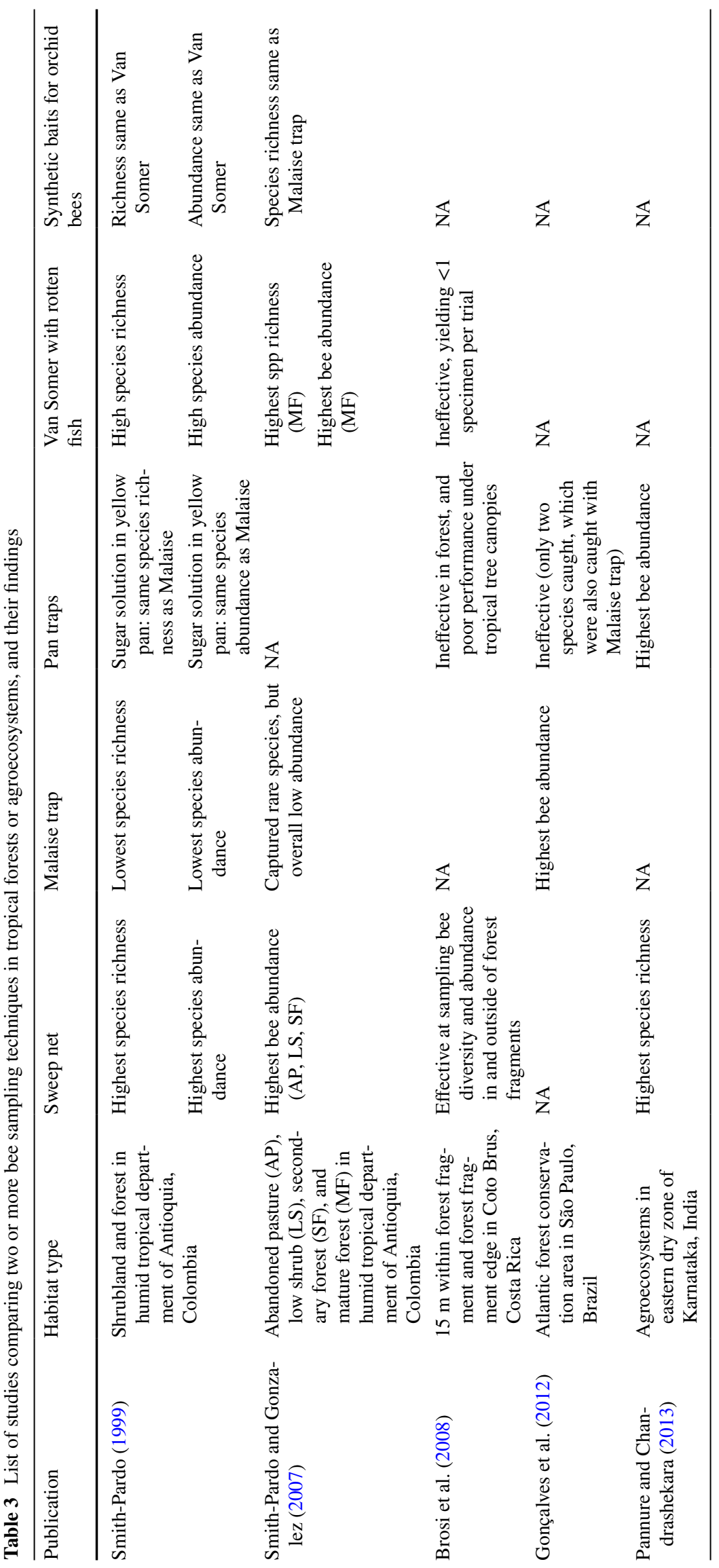


often under represented (Cane et al. 2000; Roulston et al. 2007; Popic et al. 2013). Additionally, trap placement can significantly affect bee captures (Droege et al. 2010). Pan traps provide visual cues detected by bees, with highest capture rates in full sun. For this reason, pan traps are not ideal for sampling under forest or agroforest canopies (Campbell and Hanula 2007; Brosi et al. 2008; Gonçalves et al. 2012; Droege 2015). Most often, pan traps are set on the ground (e.g. Aizen and Feinsinger 1994; Cane et al. 2000; Roulston et al. 2007; Gonçalves and Oliveira 2013), and have higher capture rates when placed in freshly mown areas or areas of bare soil in order to avoid obstructions by plant materials (Droege et al. 2010; Popic et al. 2013). When pan traps are placed near flowering plants, the plants themselves may create competing visual cues for bees resulting in lower pan trap catch (Cane et al. 2000; Roulston et al. 2007; Baum and Wallen 2011; Popic et al. 2013). This can be avoided by modifying the spacing (both vertical and horizontal) of the pan traps with respect to the distance between flowering plants (see Pan trap "Advantages").

While changing the liquid solution in the pan traps can help prolong the amount of time the traps can be left out, the traps are still vulnerable to the elements. In hot, dry, and windy areas, the liquid can evaporate rapidly, and in humid and wet environments, the liquid can overflow out of the pans (personal observation; SGP). In the former situation, the pan traps can be turned over by the wind. Gluing a heavy object to the underside of the pan (like a metal washer) can prevent bee sample losses by bowl turn-over. A potential measure to avoid liquid overflowing by rain-especially if traps are left out long periods-is to make a hole in the side and cover it with a mesh (personal observation, JAF), controlling the exact maximum level of liquid in the pan trap, without losing bees. However, this would be more advisable if high quality plastic cups are used, rather than the common disposable ones.

Distance between pan traps can change total bee capture per bowl; if the bowls are too close together, competition between traps can reduce bee captures (Droege et al. 2010). To avoid this, Droege et al. (2010) suggest placing bowls 3-5 m apart. Lastly, as bowl color has been shown to affect bee capture (e.g. Leong and Thorp 1999; Campbell and Hanula 2007), it is recommended that fluorescent blue, yellow and white bowls should be used for best results (Leong and Thorp 1999; LeBuhn et al. 2003; Roulston et al. 2007; Campbell and Hanula 2007; Grundel et al. 2011).

\section{Baits}

Any substance that attracts a bee can be considered bee bait (Schauff 1986). Baits can be used as lures, attracting bees to an area for collection with a sweep net or a kill jar (Janzen et al. 1982; Roubik 2001; Pearson and Dressler 2009;
Ramírez et al. 2010), or as bait traps (Liow et al. 2001a; Knoll and Santos 2012; Carvalho et al. 2012a). Bait traps are highly variable (see below), and include Van Someresen traps (also known as Van Somer trap; Fig. 1c) (Smith-Pardo and Gonzalez 2007; Brosi et al. 2008; Brosi 2009), McPhail traps (Becker et al. 1991), Petri dishes with bait (Liow et al. 2001a) and yellow funnel traps (Liow et al. 2001a; Roubik 2001). A review of the use of baits and bait traps in the tropics, and the interpretation of their data, are discussed in Nemésio (2012) and Nemésio and Morato (2006).

\section{Advantages}

The main advantage of baits is their effectiveness in attracting orchid bees (Tribe: Euglossini) (Janzen et al. 1982; Tonhasca Jr. et al. 2003; Nemésio and Morato 2006; Nemésio and Silveira 2006; Melo et al. 2009; Pearson and Dressler 2009; Ramírez et al. 2010; Knoll and Santos 2012), whose males are attracted to the bait odors, and also collect aromatic compounds (Dodson et al. 1969). Orchid bee flight is so rapid that they are infrequently collected using other methods (Dressler 1982). When sweep nets are used to catch bees attracted to bait, the collection rate is on average 4.7 times greater than at bait traps alone (Nemésio and Morato 2006). Furthermore, since baits target euglossine males, this method has the advantage of yielding a large number of bees without affecting the population's reproductive capabilities (Dressler 1982).

Baits are also occasionally used to sample taxa other than orchid bees. For example, honey baits have been used to attract meliponine bees in Costa Rica (Breed et al. 1999), survey bee diversity in the Bornean forest (Eltz 2004), and assess time-place learning in Trigona amalthea workers (Breed et al. 2002). However, honey baits show variable effectiveness. For example, in a different Costa Rican study surveying bee diversity in riparian forests, honey baits failed to attract some bee species (including meliponines), which were observed foraging on nearby flowers (personal observation, JAF). Another application of scent baits includes surveying nocturnal bees (Carvalho et al. 2012b).

\section{Disadvantages}

Inconsistent bait sampling protocols are a major disadvantage and make data interpretation and comparisons between studies difficult (see Sydney and Gonçalves 2015). Studies vary in the type and quantity of baits used; the time of day and duration of when the bait is used; distance between baits; and capture methods, each of which can alter the interpretation of results. For instance, there is a large variation in the type and quantity of baits used in either bait traps or lures. The majority of studies reviewed used 2-6 baits per study (Janzen et al. 1982; Becker 
et al. 1991; Breed et al. 1999; Roubik 2001; Tonhasca Jr. et al. 2003; Melo et al. 2009; Brosi 2009; Knoll and Santos 2012; Schüepp et al. 2012), but two studies used as many as 13-20 (Nemésio and Silveira 2006; Pearson and Dressler 2009). Among the studies reviewed, the most common baits were methyl salicylate, skatole, eugenol, vanillin and cineole. Very few studies justified the selection of specific baits used (e.g. Schüepp et al. 2012; Janzen et al. 1982), and even fewer investigated the effectiveness of baits at attracting the targeted bees (see Ramírez et al. 2010). This unsubstantiated use of baits results in many studies using baits that may be unattractive to certain bee species (Janzen et al. 1982), or target bee groups, and as a result, surveys of the local bee population are unsuccessful (e.g. Breed et al. 1999). Additionally, some species are simply not attracted to any known synthetic fragrance (e.g. Eulaema seabrai) (Nemésio 2012). Therefore, conclusions about bee abundance and species diversity are difficult to reach when using baits as the sole collection method.

Inconsistency in the time of day the baits are set out and the length of time they are left out can also cause variation in bee captures and limit comparisons between studies. Orchid bee perfume gathering is greatest in the morning hours, and becomes sporadic in the afternoon (Dressler 1982). Therefore, surveys in the afternoon may under-represent the local bee population. The amount of time baits are left out can also affect findings, but times reported in the literature vary from $30 \mathrm{~min}$ to a week (Liow et al. 2001b; Schüepp et al. 2012). Such differences in sampling duration can be problematic because some baits volatilize rapidly, and therefore require investigators to replenish the chemicals (Nemésio and Morato 2006). Unfortunately, no studies reviewed herein explain how to determine when to replenish baits. Additionally, orchid bees are capable of learning bait locations and becoming regular bait visitors (trapliners). The number of bees attracted to the baits may be disproportionately high when bees become trapliners (Dressler 1982; Armbruster 1993), or if the bait scents are too strong due to premature or unnecessary replenishment (Nemésio 2012).

Similarly, distance between baits is not standardized. For example, when baits are placed less than $150 \mathrm{~m}$ apart, the scents may overlap considerably and draw bees from overlapping areas, thus masking local bee faunal heterogeneity (Armbruster 1993). Due to the unknown dispersal distance of the scents used in baits, it is difficult to determine bee representativeness, and bee habitat preferences based on bait surveys. One way of dealing with this is to place greater weight on observations occurring right after bait placement (e.g. 0-5 and 5-15 min) than those occurring later (15-30 min after bait placement). The latter observation period will most likely include bees brought in from farther distances than the former.
Baits also create confusion regarding bee foraging ranges and habitat. Studies using baits are often focused on sampling the bee populations in a given habitat (Liow et al. 2001a; Eltz 2004; Nemésio and Silveira 2006; Pearson and Dressler 2009), or on determining whether habitat fragmentation affects the local bee population (Becker et al. 1991; Tonhasca Jr. et al. 2003; Brosi 2009). Orchid bees are capable of flying very long distances ( 20 km) (Dressler 1982), and even across forest fragments and open patches. Therefore, the bees collected by the bait trap may not represent the bee fauna in the immediate area. Further, most studies place the baits in forests between 1-2 $\mathrm{m}$ above ground level (Becker et al. 1991; Liow et al. 2001a; Knoll and Santos 2012), yet these baits may be drawing bees from the forest canopy (Nemésio 2012).

Given the obvious differences in collecting rates between baiting methods (Nemésio and Morato 2006) and potential factors influencing the abundance and diversity of collected bees, We recommend that, in the context of population surveys, baiting should only be used to complement other techniques, and that bait deployment methods be precisely reported.

\section{Malaise traps}

The Malaise trap (Fig. 1e) is the most common passive flight-intercept trap used to collect insects (Matthews and Matthews 1970; Peck and Davis 1980; Masner and Goulet 1981; Noyes 1989; Vardal and Taeger 2011); it is especially effective for collecting Hymenopterans, Dipterans and Lepidopterans (Malaise 1937; Gressit and Gressit 1962; Heraty and Gates 2003; Brown 2005; Chay-Hernández et al. 2006; Tangmitcharoen et al. 2006; Missa et al. 2008; Van Achterberg 2009; Kumar et al. 2009). The Malaise trap, originally developed for collecting insects in the tropical forests of Burma (Malaise 1937), continues to be a preferred method of insect collection in tropical climates (Noyes 1989; Bragança et al. 1998; Pinheiro et al. 2002; Reyes-Novelo et al. 2009; Aguiar and Santos 2010).

Minor design modifications can increase the efficiency of malaise traps for collecting target groups of insects. To increase the number of Hymenoptera captures, Masner and Goulet (1981) changed the mesh roof to a plastic roof and added a bottom foil collecting trough in addition to the top collecting head. They also impregnated the central panel with pyrethroid insecticide to more rapidly kill any intercepted insects or insects that were not strongly phototactic (Masner and Goulet 1981). Hoisting the Malaise trap into the canopy can also improve trap capture, especially in tropical forests (Faulds and Crabtree 1995). Malaise traps can also be combined with other trapping methods to improve efficiency. For example, Campos et al. (2000) placed one large yellow pan trap on the ground by the Malaise trap at a 
research station in Brazil, near secondary forest. This modification increased trap capture of Hymenoptera, Homoptera, Diptera and Thysanoptera. The ability to easily modify and add to the Malaise Trap is one of the many advantages of using this collecting method (Marston 1965).

\section{Advantages}

The Malaise trap is easy to assemble, install (Bartholomew and Prowell 2005), service and maintain (Missa et al. 2008). Changing or transferring the contents of the collecting head is extremely simple (Missa et al. 2008). In tropical climates, properly covering the bottom portion of the collecting head with fabric or aluminum foil can reduce evaporation rates of the collecting fluid (if in part ethanol) (personal observation; HTN). Compared to an open trap such as pan traps or vane traps, the closed collection head has slower evaporation rates and does not overflow when it rains. Therefore, this trap can be left out in almost all weather conditions for extended periods of time (Gressit and Gressit 1962; Leather 2005; Van Achterberg 2009). Given the little man power required to maintain the trap function, the Malaise trap is regarded as a relatively cost effective collecting method (Gaston et al. 1996; Bartholomew and Prowell 2005; Fraser et al. 2008). Malaise traps also have the advantage of collecting very rare species (Smith-Pardo and Gonzalez 2007), including Chlerogella species (Engel and Rasmussen 2013). All known bee specimens belonging to the genus Chlerogella have been caught with Malaise traps, flight intercept traps, and a single specimen was collected from a light trap (Engel and Rasmussen 2013).

Another advantage of using a Malaise trap, as with other passive sampling techniques, is that trap capture is not dependent on the experience or capability of the collector. Collecting the specimens from the trap can be as simple as emptying the contents of the collection bottle and refilling the liquid. However as trap placement can be important, researchers must be knowledgeable regarding proper trap location and orientation (see Malaise trap "Disadvantages").

\section{Disadvantages}

One of the biggest disadvantages of using the Malaise trap is its sensitivity to trap placement (Gressit and Gressit 1962; Matthews and Matthews 1970). Trap captures can vary by $50 \%$ within the same micro-habitat if placed improperly (Van Achterberg 2009). Malaise traps need to be placed in an "insect funnel" or corridor, along vegetation edges (Bettes 1986; New 1998), landscape borders (Malaise 1937), along transition zones (right angles to edges of different habitat types) (Gressit and Gressit 1962), at intersections (Leather 2005), perpendicular to a barrier (Van Achterberg 2009), or atop flower beds (Marston 1965). Furthermore, aiming the collecting head toward the sun and exposing the Malaise trap to full sun allows for more insects to be trapped (Marston 1965). When possible the back of the trap should be flush with vegetation or a border (Townes 1972).

Another disadvantage of using the Malaise trap to collect insects is the inability to associate collected insects with the surrounding flora. Many bees captured by the Malaise trap may be "tourists" simply passing through, neither visiting nor pollinating the surrounding flora nor residing in that area or habitat. This is a disadvantage with using any passive trap.

As mentioned above, the Malaise trap can be a relatively cost effective collecting method (Gaston et al. 1996; Bartholomew and Prowell 2005; Fraser et al. 2008) but because of its large size and visibility, Malaise traps are vulnerable to tampering, vandalism, theft, and destruction by animals (personal observation; HTN, SGP). Abiotic factors can also damage Malaise traps. For example, high wind speeds can rip the fabric, and uproot Malaise traps (Leather 2005). Therefore, one of the limitations of using a Malaise trap is that it cannot be used in windy, exposed sites (Leather 2005). Furthermore, in sunny, exposed sites, the mesh can wear out and change color over time due to the sun, the wind, or a combination of both (personal observation; HTN). Another drawback of using the Malaise trap as a collecting method in the forest understory is that it captures only insects flying low in the vegetation, and not those in the canopy (Missa et al. 2008). The Malaise trap is also biased in favor of collecting certain groups such as sweat bees (genus Lasioglossum) (Nardone 2013; Ngo et al. 2013). Lastly, because the Malaise trap is efficient at capturing a large abundance and variety of insects (LeBuhn et al. 2007), the processing time is quite high (Harris and Burns 2000; Grootaert et al. 2010).

\section{Sweep net}

Using a sweep net (Fig. 1d) to collect bees and other pollinators in the tropics is a very common active sampling method (Arun and Vijayan 2004), which some would argue is the most efficient insect collecting method in the tropics (SmithPardo and Gonzalez 2007; Bashir et al. 2013). There are two main sweep netting methods used: discriminate sweeping and random indiscriminate sweeping. The latter often involves a continuous movement of the net along a survey area, while the former depends on actually seeing the insect, and then sweep netting to collect it (Laroca and Orth 2002).

Sweep nets have different net fabric, color and size, handle/net length, net ring diameter, and in some cases the shape of the net ring. The most popular fabrics for the net mesh are durable cotton or linen (Yi et al. 2012). One recent modification of the net is the addition of a ziploc bag at the end of the fabric (Sepsenwol 2015). This allows for easy removal of the contents from the net. To facilitate transport into the 
field, researchers can also select collapsible or foldable nets. Collapsible nets have aluminum handles made of multiple sections that can be taken apart for compact storage, and added-on to reach the desired length. The most common handle length is 36 inches, but they frequently range from 24 to 60 inches.

\section{Advantages}

The sweep net is very easy to use, portable, cost effective, and light (Buffington and Redak 1998; Southwood and Henderson 2000; Yi et al. 2012). Additionally, there is no set up time required, unlike other collecting methods (e.g. pan traps, Malaise traps). Random indiscriminate sweep netting has many advantages, the greatest being that you may catch small, fast-flying inconspicuous bees, which would normally be missed during discriminate sweep netting (Laroca and Orth 2002). If bees are being collected to conduct analyses on spatial/temporal bee assemblages, sampling a given flower patch for an extended period of time, is not recommended (Laroca and Orth 2002). In fact, to avoid bias, protocols often explicitly state that collectors should walk at a constant, slow speed, while collecting along a transect (Buffington and Redak 1998; Laroca and Orth 2002), or should collect as many individuals as possible at one time, and then move on (Sakagami et al. 1967). Overall, the sweep net is seen as a good method for collecting and comparing relative insect diversity and abundance at experimental sites with similar habitat types (Yi et al. 2012). Furthermore, with discriminate sweep netting, links to plant-pollinator interactions or knowing floral hosts can be identified. In fact, sweep netting can be used to identify bees visiting specific flowering trees (Frankie et al. 1997, 2005, 2009); however, in such studies, conclusions can only be drawn regarding relative abundance or richness of the bee species observed (Momose et al. 1998).

\section{Disadvantages}

Currently there is no standard protocol for bee sampling using a sweep net in the tropics. This a big disadvantage for entomologists as it makes comparing bee abundance and diversity from one study to another extremely difficult. Sweep netting protocol can vary with regard to time spent sweep netting, time of day, number of aerial sweeps, number of collectors per transect, distance and/or area swept, and discriminate versus indiscriminate sweeping (Frankie et al. 1997; Laroca and Orth 2002; Arun and Vijayan 2004; Smith-Pardo and Gonzalez 2007; Bashir et al. 2013). For instance, Arun and Vijayan (2004) swept 100 times along a $1.5 \mathrm{Km}$ transect, Bashir et al. (2013) swept for two 60-min periods over an unspecified distance, and Frankie et al. $(2005,2009)$ had two collectors sweep 96 times, around one specific tree. Further, with discriminate sweep netting, there is a lower chance of catching sensitive, fast-flying insects (Laroca and Orth 2002), thereby, leading to sampling bias towards more conspicuous, louder, slower, and less reactive bees (Sakagami et al. 1967). Unfortunately, some studies failed to state specifics regarding sweep net protocol and/or equipment type, thus limiting its replicability (Table 1).

One of the greatest disadvantages of using sweep nets is that the capture rate and/or total capture can vary with each collector's efficiency, skill level, and their sampling bias (Sakagami et al. 1967; Laroca and Orth 2002; Yi et al. 2012). This can result in two very different bee captures even if sampling is conducted at the same site (Laroca and Orth 2002). Experimental methods and data analyses can be adjusted to diminish the effects of collector's bias (e.g. alternate collectors, include collectors in data analyses). Another disadvantage of the sweep netting method is the removal and killing of insect specimens. This may have an effect on the total remaining bee fauna/assemblage present in that area, especially if the bee is rare (Laroca and Orth 2002; but see Gezon et al. 2015). This is not typically the case and this disadvantage can be said for any of the sampling methods with the exception of a capture and release sweep netting method and visual observations (Laroca and Orth 2002).

When using the sweep net method, environmental conditions must be optimal and constant as bee activity can vary with changing conditions (Sakagami et al. 1967; Inoue et al. 1993; Rader et al. 2013). For example, variations in weather conditions such as temperature and wind velocity can affect total insect capture when sweep netting; this may vary from day to day and also throughout the day (i.e. microclimatic variation) (Romney 1945; Hughes 1955; Doxon et al. 2011b; Rader et al. 2013). Therefore, it is important to have similar collection times and temperatures in order to compare captures. Collection times can range anytime from early morning, to early afternoon, or all day, depending on the study objective (Frankie et al. 1997; Smith-Pardo and Gonzalez 2007; Bashir et al. 2013). For example, Frankie et al. (1997) collected bees mid-day, because that was the longest period of strong nectar production in their plant of interest (Andira inermis). Sweep nets can also be used to study crepuscular bees (Harrison et al. 2005).

Local vegetation can also affect sampling with the sweep net, so sweep netting is usually limited to open habitat systems (Yi et al. 2012). Sweep netting in a forest understory or dense forest patches with thorny/spiny plants can be difficult, and certain areas may be under-sampled because the net can get easily caught and torn (Laroca and Orth 2002). In more open understory sites collections can also be biased towards insects near the outside of the vegetation or within reach of the sweep net (Buffington and Redak 1998; Doxon et al. 2011a). So, canopy or insects foraging in hard-to-access 
areas may be under-sampled with a sweep net (Laroca and Orth 2002).

Other disadvantages include the large amount of time and energy spent sampling, compared to passive sampling methods (e.g. malaise traps) (Yi et al. 2012). Because this method is labor intensive with many man hours needed, it is not suitable for long-term, large-scale projects (Bashir et al. 2013). Finally, insect specimens may be damaged when using an insect net for collection (Doxon et al. 2011a), which can make species identification extremely challenging.

\section{Timed observations}

Timed observations involve visually counting and identifying bees over a set period of time. These observations can take place in a survey plot, transect, on a whole plant or part of it, around a nest, or a combinations of these (Southwood and Henderson 2000). Although it is easy to measure total bee abundance using timed observations, counting abundance by species could be more challenging.

\section{Advantages}

The main advantage of timed observations is its efficiency. This high efficiency comes from the large amount of data that can be collected over a short time-span and at low economic cost. Assuming that bee capture and processing is minimal, almost no equipment is needed. Otherwise, alternative sampling methods could be more appropriate. In addition to efficiency, timed observations have a wide range of applications and can be used to obtain detailed bee behavioral information. Floral association is one of the simplest and most common examples (Cane 2001; Florez et al. 2002; Ricketts 2004; Price et al. 2005; Leonhardt et al. 2011; Rocha-Filho et al. 2012; Lemaitre et al. 2014), but more complex interactions such as pollination and communication studies also benefit from direct observations.

With regard to pollination studies, visitation rates are most often measured (Klein et al. 2003b; Ricketts 2004; Vergara and Badano 2009; Jha and Vandermeer 2009). Key information including duration, location and extent of the observation is necessary to guarantee data quality that fits analyses requirements. For instance, to measure bee visitation rates (number of bees visiting a set number of flowers) in coffee, Ricketts (2004) used the number of visits per 100 flowers per 20-min observation period. This procedure was done simultaneously by two people for each survey site, to minimize observer bias and site effects. Short pilot studies can help unveil challenging situations and identify adequate observation times and flower/tree numbers.

Video recording and time-lapse photos are special types of timed observations that are increasing in popularity (Lortie et al. 2012; Rodríguez-Oseguera et al. 2013; Lemaitre et al. 2014; Edwards et al. 2015). Compared to regular timed observations, video recording is a passive sampling technique allowing longer observation periods, even in conditions that could be difficult for people to work in. For example, nocturnal floral visitors can be recorded using infrared cameras (Rodríguez-Oseguera et al. 2013; Lemaitre et al. 2014). Video footage from such recordings can provide information on bee richness, visit time and visit duration. This can allow observers to identify floral visitors over the entire bloom time of a flower, and provide pollen placement and fruit set records (Edwards et al. 2015). Being a passive method, video recording can also reduce observer bias which is a common problem when the field crews include technicians with varying levels of expertise (Westphal et al. 2008). Climatic bias that results from different sampling times can also be reduced if all sites/sample units within the same climatic regime are evaluated simultaneously (assuming enough equipment is available for all sites). Additionally, no expertise nor time in the field is needed other than for setting-up and dismantling the recording equipment. In the two aforementioned studies, insects were identified by specialists during playback sessions after field recording.

\section{Disadvantages}

Disadvantages of timed observations are mostly related to species determination. Identifying foraging bees to species level in the field can result in incorrect or limited (e.g. morphospecies) determinations (Kremen et al. 2011), even if the observers are expert taxonomists. In a study assessing the abilities of citizen scientists to correctly identify and detect flower-visiting pollinators, lower-level taxonomic data (genus or species) detected by citizen scientists who were trained for $10 \mathrm{~h}$, were very different from observations made by trained professionals using sweep nets (Kremen et al. 2011). Depending on the study goals and the level of bee identification accuracy required (i.e. taxonomic level of identification), specimen captures should be included in the protocol. This unfortunately decreases this method's efficiency, as capturing bees involves allocating time to transfer specimens into labeled containers as they are captured, thus adding to the observation time.

Timed observations are therefore better suited to studies focused on a particular crop or plant species where bees are easy to identify, minimizing the need for captures. In a study carried out in Mexico by Vergara and Badano (2009), all bee species visiting coffee flowers (seven species) were determined in situ by one of the authors, who was a specialist in the local bee fauna. A different strategy was used by Ricketts (2004), who had no bee experts in the field to evaluate flower visitation rates in coffee plantations in Costa Rica: prior to timed observation, a species-level reference collection was created for the study site, and descriptive names given to 
each morphospecies (personal observation; JAF). During timed observation, bees were assigned to morphospecies, and the few that did not match any morphospecies were captured with aspirators for later identification (personal observation; JAF). In a similar study of coffee pollinators in Indonesia, Klein et al. (2003b) used a different approach: they captured bees for $5 \mathrm{~min}$ right after each 25 -min period of flower visitor observations to validate their identifications. Using this method, a total of 29 bee species were identified. In Mexico, Jha and Vandermeer (2009) observed bees during periods of $15 \mathrm{~min}$, to determine the duration of bee visits and the number of flowers visited by each bee. When possible, bees were captured after the observation period for identification (Apis mellifera and 16 native bees) (Jha and Vandermeer 2009). Even when supplemented with a reference collection, field identification during timed observation can be biased against smaller species, which are harder to identify (Ricketts 2004). Such was the case for Ricketts (2004) wherein small, difficult to identify bee species were grouped as "unknowns" as they could not easily be matched to a preassigned morphospecies (personal observation; JAF). This could not only limit the possibility to identify the species, biasing species richness, but could potentially decrease the recorded observations, biasing total abundance.

With regard to video recordings, disadvantages include the high cost of equipment and video processing, and logistical difficulties involved with setting equipment up in the field. Additionally, vigilance is needed in many situations to avoid vandalism or equipment losses by theft. This could counteract the advantages of the passive nature of the method. Also, even with high taxonomic expertise, some bees could still be impossible to identify to species based on the recordings. This limitation obviously increases as the bee size decreases and it could potentially create the same size bias as direct observation.

\section{Aspirators/pooters}

Aspirators are a precise method of capturing insects. They can be used not only to capture bees directly in the fielde.g. visiting flowers or plant resin sources-but also to support other capture techniques, such as removing bees from inside a sweep net or attracted by light traps (Southwood and Henderson 2000). An aspirator is one flexible hose and a stiff tube connected by a stopper in a vial (Schauff 1986). When using an aspirator, the person puts the end of the stiff tube close to the bee and sucks sharply through the end of the flexible hose. This draws the bee into the stiff tube and finally into the vial. A small piece of mesh cloth is attached to the end of the flexible hose, which is inserted through the stopper, and prevents the bee from being sucked into the collector's mouth (Schauff 1986). Aspiration power can be increased by using a larger diameter flexible hose and a smaller diameter (as small as the largest targeted bee species) stiff tube (ASME 1971). Although high suction power can enhance capture efficiency, Michener et al. (1955) warned about the increased probability of damaging bees when they strike the hard glass/plastic of the container. A little cotton placed at the bottom of the aspirator vial can easily solve this potential problem (Michener et al. 1955).

\section{Advantages}

Aspirators are a gentle and precise sampling method suitable when the objective is to remove insects without damaging any plant materials (e.g., branches, leaves and flowers). As such, aspirators can be ideal in agricultural settings. They can be very useful in coffee plantations during massflowering events, when the coffee plants are heavily loaded with flowers (Klein et al. 2003b). For Florez et al. (2002) and Ricketts (2004), aspirators were key to capturing bees landing in flowers deep in a coffee bush or on the opposite side of a planting row. Aspirators are also convenient when thorny and dense vegetation is dominant. Due to their small size, aspirators can conveniently be kept within reach (e.g. in pockets), or hung around the neck, making them very accessible when needed quickly.

Aspirators can also be a good tool for mark-recapture studies. For example, aspirators were used to capture, mark and release $M$. panamica foragers in a study assessing recruitment communication (Nieh et al. 2003a, b). Markrecapture data can also be used to study bee flight, inter-tree movement and time spent foraging on a particular plant or in a particular habitat (Frankie et al. 1976, 2009; Carroll et al. 1991). In addition to providing information on bee behavior, mark-recapture studies offer greater inferential power about demographic parameters (e.g., species abundance; Roubik and Aluja 1983; Southwood and Henderson 2000), but they require a suitable means of marking bees and repeated periods of mark-recaptures to have sufficient encounter histories required for analyses.

Aspirators are a slow capturing tool because captures go one by one, especially if the collector is inexperienced. However, this low efficiency can be counteracted when sampling protocols allow captures to be accumulated in the aspirator (i.e. when all captured bees belong to the same sampling unit/period). This reduces the time of sample processing in the field, increasing the effective sampling time. Since aspirators are easy to make, we recommend a system where the aspirator container can be easily replaced to spend less time handling bees in the field. Thus, when a new bee sample is needed, the two hoses are detached from the container, the two holes in the container closed by a cork-like plug, and a new empty container installed to start a new sample. This eliminates the transferring process (bees to vials, labeling), which saves time and reduces specimen escape or damage. 
Labels can be placed inside empty containers before the collection period starts.

\section{Disadvantages}

Aspirators may not be very effective at capturing bees that are sensitive, fast flyers. This can potentially bias study results, especially those assessing bee species richness and community structure. Additionally, aspirators are more efficient for small bees; honeybee size is about the maximum targeted. Trying to catch larger bees is still possible but presents a design challenge in that it requires strong suction even as hose diameter is increased to fit the bee size (ASME 1971). An example of this limitation is shown by Hoehn et al. (2008), who restricted their aspirator use to small bees visiting pumpkin flowers in Indonesia.

Aside from mark-recapture studies, most studies using aspirators to sample bee populations also use sweep nets and visual observations (Florez et al. 2002; Ricketts 2004; Chacoff and Aizen 2016). Since aspirators alone are not effective at capturing all bee species in the population, we recommend they be used in combination with one or more of the methods reviewed above.

\section{Discussion}

We reviewed over 150 peer-reviewed publications that used six common bee sampling methods in the tropics. The review shows little consensus on which method or combination of methods would be most effective for sampling bee populations in tropical landscapes. Nonetheless, we summarize the findings from this review in two tables: Table 1 provides recommendations on which method may perform better under their specific budget constraints (time, cost, person-power, etc.), and in Table 2, we provide recommendations on the use of specific methods for specific research questions and habitat types. To further inform this decision, we also discuss the main findings of the few studies that have compared two or more sampling methods in the tropics and summarize them in Table 3.

While a number of studies have assessed the efficiency of bee sampling methods in temperate regions (Cane et al. 2000; Roulston et al. 2007; Campbell and Hanula 2007; Wilson et al. 2008; Baum and Wallen 2011; Grundel et al. 2011; Geroff et al. 2014), few have done so in tropical forests (Smith-Pardo and Gonzalez 2007; Brosi et al. 2008; Gonçalves et al. 2012; Pannure and Chandrashekara 2013). We found that several studies assessed the relative effectiveness of sweep nets, pan traps, bait traps and malaise traps, but we found only one that did so for timed observations and none for aspirators. Unfortunately, the study on timed observations compared the accuracy of visual observations by citizen scientists to the captures of trained professionals using sweep nets (Kremen et al. 2011). Thus, differences between the two groups could have been due to methodological differences. The lack of studies assessing the accuracy of timed observations is worrisome because this is a very commonly used method in tropical agroforest systems (e.g. Aizen and Feinsinger 1994; Vergara and Ayala 2002; Klein et al. 2003b; Jha and Vandermeer 2009).

In our review, only five studies compared sampling methods in tropical forests (Smith-Pardo 1999; Smith-Pardo and Gonzalez 2007; Brosi et al. 2008; Gonçalves et al. 2012; Pannure and Chandrashekara 2013; Table 3). Four of these studies used sweep nets (Smith-Pardo 1999; SmithPardo and Gonzalez 2007; Brosi et al. 2008; Pannure and Chandrashekara 2013), three used pan traps (Brosi et al. 2008; Gonçalves et al. 2012; Pannure and Chandrashekara 2013), one used yellow pan traps with a sugar solution as bait (Smith-Pardo 1999), three used Malaise traps (SmithPardo 1999; Smith-Pardo and Gonzalez 2007; Gonçalves et al. 2012), three used rotten fish baits in Van Somer traps (Smith-Pardo 1999; Smith-Pardo and Gonzalez 2007; Brosi et al. 2008), and two used synthetic baits specific for orchid bees (Smith-Pardo 1999; Smith-Pardo and Gonzalez 2007). There was agreement that sweep nets caught the highest numbers of bees (Smith-Pardo 1999; Smith-Pardo and Gonzalez 2007; Brosi et al. 2008), providing a basis to estimate species richness, evenness, and when combined, an estimate of species diversity. Sweep nets were effective in agroecosystems, abandoned pastureland, low shrub, and secondary forests. Compared to rotten-fish-baited Van Somer traps, yellow pan traps with sugar solution, malaise traps and orchid bee bait traps, Smith-Pardo (1999) found sweep nets to be the most effective method both in the low shrub and the mature forests of Colombia. However, in a later study in the same region of Colombia, Smith-Pardo and Gonzalez (2007) found rotten-fish-baited Van Somer traps to perform best in mature forests, with the highest species richness and abundance being captured, compared to sweep nets, malaise traps and orchid bee bait traps. Interestingly, Smith-Pardo (1999) reports that the rotten fish bait in the Van Somer traps and the orchid-bee bait traps caught bees from a range of families, not just Apidae (Smith-Pardo 1999). In the mature forests of Costa Rica, however, Van Somer traps baited with rotten fish were extremely inefficient at capturing bees (Brosi et al. 2008). Malaise traps were best at measuring bee species richness near Sao Paulo, Brazil (Gonçalves et al. 2012). Additionally, about $50 \%$ of rare bee species (represented by only one specimen) were captured using Malaise traps in Colombia (Smith-Pardo and Gonzalez 2007). Pan traps were found to be ineffective in forests (Brosi et al. 2008; Gonçalves et al. 2012), and adding a sugar solution to yellow pan traps did not improve bee captures (Smith-Pardo 1999). In an agroecosystem in dry zone of Karnataka, India, pan traps 
caught a high abundance and richness of bees, though the overall number of species was lower than that caught with sweep nets (Pannure and Chandrashekara 2013). Though the authors provide little description of the agroecosystem and its surrounding areas, we suspect that the study area was not densely treed, leading to the effectiveness of the pan traps. As in open temperate regions, the authors also found complementarity between sweep net captures and pan trap captures, further supporting our assumptions regarding the habitat.

Tropical systems pose unique sampling challenges including dense and tall forest canopies, dense understory vegetation, heavy and frequent rainfall, and high temperatures, humidity and UV (i.e. sunshine). Our review highlights multiple sources of bias and lack of information to isolate site, trap, and collector-induced biases. In light of these factors and the potential of sampling hyper-diverse groups, we recommend using complementary methods to increase sampling efficiency in estimating abundance and species richness (Longino and Colwell 1997). Thus, if working in open tropical systems (including agroecosystems), we suggest that pan traps, Malaise traps, and sweep nets are complementary methods. Conversely, if surveying bees in forested areas, then we suggest concurrently using Malaise traps, sweep nets, and baits (Table 2).

\section{Recommendations to facilitate multi-study inferences}

Specifying methodological approaches to compare or combine results from multiple studies across the tropics is not within the scope of our review; however, in order to facilitate future meta-analyses we outline several steps to derive broader inferences and insights about bee responses to experimental treatments or conservation threats (Cooper et al. 2009). A clear first step is to ensure researchers provide detailed information about their study experimental design, trapping methods, and report precision estimates for demographic or community-level parameters (e.g., abundance, species richness). We also stress the importance of reporting catch per unit effort (CPUE) to standardize results across studies (Colwell et al. 2004). For example, estimates of species richness can be derived from species accumulation curves (i.e., how fast species in a community are captured per unit of effort; Longino and Colwell 1997; Ugland et al. 2003; Colwell et al. 2004). Information on CPUE is valuable because accumulation rates can be influenced by many factors (e.g., behavior, seasonal temperature, trap selectivity, habitat), and in some cases, comparative studies might require using a unit of effort that minimizes potential biases (Moreno and Halffter 2000; Willott 2001). Moreover, understanding variation in CPUE across trapping methods and taxonomic groups is necessary to determine which methods are complementary and which yield the highest efficiency.
Efficiency in this context refers to the rapidity with which species accumulate per unit of effort or cost (Longino and Colwell 1997). Catch per unit effort is also used as an index of population abundance or biomass (Williams et al. 2002). The index is obtained by regressing cumulative catch (numbers or biomass) and CPUE. The slope of the regression is termed 'catchability' and it is interpreted as the average proportion of the sampled population captured by one unit of sampling effort (Arregun-Sanchez 1996). We encourage authors to report catchability because it could help identify the need to standardize it to conduct comparative work, trigger the use of approaches that account for heterogeneity in catchability due to the use of different trapping methods, or simply prevent spurious inferences (Arregun-Sanchez 1996; Harley et al. 2001; Lauretta et al. 2013).

We also suggest that melittologists consider alternative estimation techniques such as occupancy analysis (MacKenzie et al. 2006). This analytical approach uses presence/nonpresence data as a means to understand patterns of species distribution in the context of changing landscapes, climate, or treatments. Inferences account for the fact that capture probability for any method is usually $<1$. We note that methods to collect presence/non-presence data are already available (e.g., sweep nets, aspirators, "bee squeezers"), requiring only that biologically meaningful sampling units (e.g., patch) are defined and sampling efforts standardized. The appeal of the approach is strengthened by the range of occupancy models suited to address multiple challenges. For example, abundance is central to our understanding of species conservation status and responses to conservation management actions (Nichols and Williams 2006). In light of the difficulties in obtaining reliable estimates of abundance, we suggest that using proxies of abundance might be a reasonable alternative. Multi-state, multi-season models address this need by yielding estimates of the probability that a site or study patch is not occupied (non-presence), occupied (one individual) or of encountering various levels of abundance defined by the researcher [e.g., few (2-5) or many ( $\geq 6$ ); Nichols et al. 2007]. Multi-season models also yield estimates of colonization and extinction rates, parameters that characterize range shifts (Yackulic et al. 2015). We highlight community-level occupancy models because declining trends involve multiple species (Dorazio et al. 2010; Pacifici et al. 2014). This modeling approach can be used to estimate species richness, with precision estimates, and gain insights about factors that influence the occupancy of species in a community (e.g., treatment, environmental covariates). Importantly, this framework allows modeling different capture/trapping probabilities that might stem from the concurrent use of different trapping methods, or heterogeneity in trapping probability associated with different species groupings in a bee community. Clearly, accounting and controlling for heterogeneity in trapping probabilities 
emphasizes the importance of carefully defining study objectives and selecting groupings that represent important guilds or taxonomic assemblages of conservation interest (Pacifici et al. 2014).

Available data suggests that bee populations are declining worldwide (Colla and Packer 2008; IPBES 2016; Solar et al. 2015; Nemésio et al. 2016; Potts et al. 2016). Curbing these trends will require carefully selected conservation actions and monitoring programs that yield not only interpretable metrics to gauge multi-species status, but also a means to measure the effectiveness of actions and whether there is a need to adjust these actions as new information is gathered (i.e., adaptive, Nichols and Williams 2006). The recommendations outlined above and raising awareness about existing analytical tools is a step towards meeting these challenges. However, we also encourage melittologists, entomologists, and quantitative ecologists to explore the possibility of developing new approaches capable of tapping multiple sources of data (Pacifici et al. 2017). This emerging body of research recognizes that many agencies, institutions and the public (i.e., citizen scientists) collect data on resources of interest (e.g., bees) over long periods of time and over wide geographic areas. In some cases, data fusion can yield stronger inferences from species distribution models (Pacifici et al. 2017). Our review helps in this endeavor by providing a basis to determine which sampling methods could be combined to improve inferences about bee status and distribution worldwide.

Acknowledgements The authors would like to thank Elsa Youngsteadt for her thoughtful comments and suggestion. This work was supported by a Federal Aid Grant from the Puerto Rico Department of Natural and Environmental Resources, and the North Carolina State University, Department of Applied Ecology. Any use of trade, firm, or product names is for descriptive purposes only and does not imply endorsement by the U.S. Government.

\section{Compliance with ethical standards}

Conflict of interest The authors declare that they have no conflict of interest.

Open Access This article is distributed under the terms of the Creative Commons Attribution 4.0 International License (http://creativecommons.org/licenses/by/4.0/), which permits unrestricted use, distribution, and reproduction in any medium, provided you give appropriate credit to the original author(s) and the source, provide a link to the Creative Commons license, and indicate if changes were made.

\section{References}

Aguiar AP, Santos BF (2010) Discovery of potent, unsuspected sampling disparities for Malaise and Möricke traps, as shown for Neotropical Cryptini (Hymenoptera, Ichneumonidae). J Insect Conserv 14:199-206
Aizen MA, Feinsinger P (1994) Habitat fragmentation, native insect pollinators, and feral honey bees in argentine "Chaco Serrano". Ecol Appl 4:378-392

Armbruster WS (1993) Within-habitat heterogeneity in baiting samples of male euglossine bees: possible causes and implications. Biotropica 25:122-128

Arregun-Sanchez F (1996) Catchability: a key parameter for fish stock assessment. Rev Fish Biol Fish 6:221-242

Arun PR, Vijayan VS (2004) Patterns in abundance and seasonality of insects in the siruvani forest of Western ghats, nilgiri biosphere reserve, southern India. Sci World J 4:381-392

ASME (1971) Fluid meters: their theory and application. In: Bean HS (ed) American Society of Mechanical Engineers (ASME), 6th edn. Research Committee on Fluid Meters, New York

Bąk-Badowska J (2012) Spatial diversification of Bee (Hymenoptera: Apoidea: Apiformes) assemblages in forest communities of the Suchedniów-Oblęgorek Landscape park. J Apic Sci 56:89-106

Bartholomew CS, Prowell D (2005) Pan compared to malaise trapping for bees (Hymenoptera: Apoidea) in a longleaf pine savanna. J Kansas Entomol Soc 78:390-392

Bashir MA, Saeed S, Sajjad A (2013) Monitoring Hymenoptera and Diptera pollinators in a sub-tropical forest of Southern Punjab, Pakistan. Pak J Agric Sci 50:359-366

Baum KA, Wallen KE (2011) Potential bias in Pan trapping as a function of floral abundance. J Kansas Entomol Soc 84:155-159

Bawa KS (1990) Plant-pollinator interactions in tropical rain forests. Annu Rev Ecol Syst 21:399-422

Bawa KS, Crisp JE (1980) Wind-pollination in the understorey of a rain forest in Costa Rica. J Ecol 68:871-876

Becker P, Moure JS, Peralta FJA (1991) More about euglossine bees in amazonian forest fragments. Biotropica 23:586-591

Bettes C 1986. The hymenopterist's handbook. In: Cribb PW, Luffoley DD (eds) 2nd edn. The Amateur Entomologist's society, Middlesex

Bragança M. A. L., Zanuncio J, Picanço M, Laranjeiro AJ (1998) Effects of environmental heterogeneity on Lepidoptera and Hymenoptera populations in Eucalyptus plantations in Brazil. For Ecol Manage 103:287-292

Breed MD, Mcglynn TP, Sanctuary MD, Stocker EM, Cruz R (1999) Distribution and abundance of colonies of selected meliponine species in a Costa Rican tropical wet forest. J Trop Ecol 15:765-777

Breed MD, Stocker EM, Bumgartner LK, Vargas SA (2002) Timeplace learning and the ecology of recruitment in a stingless bee, Trigona amalthea (Hymenoptera, Apidae). Apidologie 33:251-258

Brosi BJ (2009) The effects of forest fragmentation on euglossine bee communities (Hymenoptera: Apidae: Euglossini). Biol Conserv 142:414-423

Brosi BJ, Daily GC, Shih TM, Oviedo F, Durán G (2008) The effects of forest fragmentation on bee communities in tropical countryside. J Appl Ecol 45:773-783

Brosi BJ, Daily GC, Chamberlain CP, Mills M (2009) Detecting changes in habitat-scale bee foraging in a tropical fragmented landscape using stable isotopes. For Ecol Manage 258:1846-1855

Brown BV (2005) Malaise trap catches and the crisis in Neotropical dipterology. Am Entomol 51:180-183

Buffington ML, Redak RA (1998) A comparison of vacuum sampling versus sweep-netting for arthropod biodiversity measurements in California coastal sage scrub. J Insect Conserv 2:99-106

Campbell JW, Hanula JL (2007) Efficiency of Malaise traps and colored pan traps for collecting flower visiting insects from three forested ecosystems. J Insect Conserv 11:399-408

Campos WG, Pereira DBS, Schoereder JH (2000) Comparison of the efficiency of flightinterception trap models for sampling 
Hymenoptera and other insects. Anais da Sociedade Entomológica do Brasil 29:381-389

Cane J (2001) Habitat fragmentation and native bees: a premature verdict? Conserv Ecol 5:1-10

Cane JH, Minckley RL, Kervin LJ (2000) Sampling bees (Hymenoptera: Apiformes) for pollinator community studies: pitfalls of pan-trapping. J Kansas Entomol Soc 73:225-231

Carroll JF, Russekcohen E, Nichols JD, Hines JE (1991) Populationdynamics of American dog ticks (Acari, Ixodidae) along park trails. Environ Entomol 20:922-929

Carvalho AT, Maia ACD, Ojima PY, dos Santos AA, Schlindwein C (2012a) Nocturnal bees are attracted by widespread floral scents. J Chem Ecol 38:315-318

Carvalho AT, Maia ACD, Ojima PY, dos Santos AA, Schlindwein C (2012b). Nocturnal bees are attracted by widespread floral scents. J Chem Ecol 38:315-318

Chacoff NP, Aizen MA (2016) Edge effects on flower-visiting insects in grapefruit plantations bordering premontane subtropical forest published by: British Ecological Society Linked references are available on JSTOR for this article: edge effects on flowervisiting insects in grapefruit plantations bordering premontane. Subtrop For 43:18-27

Chay-Hernández DA, Delfín-González H, Parra-Tabla V (2006) Ichneumonoidea (Hymenoptera) community diversity in an agricultural environment in the State of Yucatan. Mex Environ Entomol $35: 1286-1297$

Colla SR, Packer L (2008) Evidence for decline in eastern North American bumblebees (Hymenoptera: Apidae), with special focus on Bombus affinis Cresson. Biodivers Conserv 17(6):1379-1391

Colwell RK, Mao CX, Chang J (2004) Interpolating, extrapolating, and comparing incidence-based species accumulation curves. Ecology 85:2717-2727

Cooper H, Hedges LV, Valentine JC. 2009. The handbook of research synthesis and meta-analysis. Russell Sage Foundation, New York

Dodson CH, Dressler RL, Hills HG, Adams RM, Williams NH (1969) Biologically active compounds in orchid fragrances. Science 164:1243-1249

Dorazio RM, Kéry M, Royle JA, Plattner M (2010) Models for inference in dynamic metacommunity systems. Ecology 91:2466-2475

Doxon ED, Davis CA, Fuhlendorf SD (2011a) Comparison of two methods for sampling invertebrates: vacuum and sweep-net sampling. J Field Ornithol 82:60-67

Doxon ED, Davis CA, Fuhlendorf SD, Winter SL (2011b) Aboveground macroinvertebrate diversity and abundance in sand sagebrush prairie managed with the use of pyric herbivory. Rangeland Ecol Manage 64:394-403

Dressler RL (1982) Biology of the Orchid Bees (Euglossini). Annu Rev Ecol Syst 13:373-394

Droege S (2015) The very handy manual: how to catch and identify bees and manage a collection. Patuxent, Maryland

Droege S, Tepedino VJ, Lebuhn G, Link W, Minckley RL, Chen Q, Conrad C (2010) Spatial patterns of bee captures in North American bowl trapping surveys. Insect Conserv Divers 3:15-23

Edwards J, Smith GP, Mcentee MHF (2015) Long-term time-lapse video provides near complete records of floral visitation. J Pollinat Ecol 16:91-100

Eltz T (2004) Spatio-temporal variation of apine bee attraction to honeybaits in Bornean forests. J Trop Ecol 20:317-324

Engel MS, Rasmussen C (2013) Revision of the bee genus Chlerogella (Hymenoptera: Halictidae), Part III: new records and a new species from Peru. J Melittology 9:1-8

Faulds W, Crabtree R (1995) A system for using a Malaise trap in the forest canopy. New Zealand Entomol 18:97-99
Florez J, Muschler R, Harvey C, Finegan B, Roubik D (2002) Biodiversidad funcional en cafetales: el rol de la diversidad vegetal en la conservación de abejas. Agroforestería en las Américas 9:29-36

Frankie GW, Opler PA, Bawa KS (1976) Foraging behaviour of solitary bees: implications for outcrossing of a neotropical forest tree species. J Ecol 64:1049-1057

Frankie GW, Vinson SB, Rizzardi M. a, Griswold TL, Keefe O, Snelling RR (1997) Diversity and abundance of bees visiting a mass flowering tree species in disturbed seasonal dry forest, Costa Rica. J Kansas Entomol Soc 70:281-296

Frankie GW, Rizzardi M, Vinson SB, Griswold TL, Ronchi P (2005) Changing bee composition and frequency on a flowering legume, Andira inermis (Wright) Kunth ex DC. during El Niño and La Niña years (1997-1999) in Northwestern Costa Rica. J Kansas Entomol Soc 78:100-117

Frankie GW, Rizzardi M, Vinson SB, Griswold TL (2009) Decline in bee diversity and abundance from 1972 to 2004 on a flowering leguminous tree, Andira inermis in Costa Rica at the Interface of disturbed dry forest and the urban environment. J Kansas Entomol Soc 82:1-20

Fraser S. E. M., Dytham C, Mayhew P (2008) The effectiveness and optimal use of Malaise trap for monitoring parasitoid wasps. Insect Conserv Divers 1:22-31

Gaston K, Gauld I, Hanson P (1996) The size and composition of the hymenopteran fauna of Costa Rica. J Biogeogr 23:105-113

Geroff RK, Gibbs J, McCravy KW (2014) Assessing bee (Hymenoptera: Apoidea) diversity of an Illinois restored tallgrass prairie: methodology and conservation considerations. J Insect Conserv 18(5):951-964

Gezon ZJ, Wyman ES, Ascher JS, Inouye DW, Irwin RE (2015) The effect of repeated, lethal sampling on wild bee abundance and diversity. Methods Ecol Evol 6(9):1044-1054

Ghazoul J (2005) Buzziness as usual? Questioning the global pollination crisis. Trends Ecol Evol 20:367-373

Gonçalves RB, Oliveira PS (2013) Preliminary results of bowl trapping bees (Hymenoptera, Apoidea) in a southern Brazil forest fragment. J Insect Biodivers 1:1-9

Gonçalves RB, Santos EF, Scott-santos CF (2012) Bees (Hymenoptera: Apoidea: Apidae s.1.) captured with Malaise and pan traps along an altitudinal gradient in the Parque Estadual da Serra do Mar, Ubatuba., São Paulo. Brazil Check List 8:53-56

Gressit JL, Gressit MK (1962) An improved Malaise Trap. Pac Insects 4:87-90

Grootaert P, Pollet M, Dekoninck W, Achterberg C. 2010. Sampling insects: general techniques, strategies and remarks. In: Eymann J, Degreef CH, Hauser JC, Monje Y, Samyn, Vandenspiegel D (eds) Manual on field recording techniques and protocols for All Taxa Biodiversity Inventries and Monitoring. ABC Taxa, pp 377-399

Grundel R, Frohnapple KJ, Jean RP, Pavlovic NB (2011) Effectiveness of bowl trapping and netting for inventory of a Bee Community. Environ Entomol 40:374-380

Harley SJ, Myers RA, Dunn A (2001) Is catch-per-unit-effort proportional to abundance? Can J Fish Aquat Sci 58:1760-1770

Harris RJ, Burns BR (2000) Beetle assemblages of kahikatea forest fragments in a pasture-dominated landscape. New Zealand J Ecol 24:57-67

Harrison RD, Nagamitsui T, Momose K, Inoue T (2005) Flowering phenology and pollination of Dipterocarpus (Dipterocarpaceae) in Borneo. Malayan Nat J 57:67-80

Heraty J, Gates M. 2003. Diversity of Chalcidoidea (Hymenoptera) at El Edén Ecological Reserve, Mexico. Page 659in Fedick S, Allen M, Jimenez-Osornio J, Gomez-Pompa A (eds) The Lowland Maya Area. CRC Press 
Hoehn P, Tscharntke T, Tylianakis JM, Steffan-Dewenter I. (2008) Functional group diversity of bee pollinators increases crop yield. Proc Biol Sci/R Soc 275:2283-2291

Hughes RD (1955) The intluence of the prevailing weather on the numbas of Meromysa variegata Meigen (Diptera, Chloropidae) caught with a sweepnet. J Anim Ecol 24:324-335

Inoue T, Nakamura K, Salmah S, Abbas I (1993) Population-dynamics of animals in unpredictably-changing tropical environments. J Biosci 18:425-455

IPBES (2016) The assessment report of the Intergovernmental Science-Policy Platform on Biodiversity and Ecosystem Services on pollinators, pollination and food production. Potts SG, Imperatriz-Fonseca VL, Ngo HT (eds) Secretariat of the Intergovernmental Science-Policy Platform on Biodiversity and Ecosystem Services, Bonn, p 36

Janzen DH, Devries PJ, Hinggins ML, Kimsey LS (1982) Seasonal and site variation in Costa Rican Euglossine bees at chemical baits in lowland deciduous and evergreen forests. Ecology 63:66-74

Jha S, Vandermeer JH (2009) Contrasting bee foraging in response to resource scale and local habitat management. Oikos 118:1174-1180

Klein A-M, Steffan-Dewenter I, Buchori D, Tscharntke T (2002) Effects of land-use intensity in tropical agroforestry systems on coffee flower-visiting and trap-nesting bees and wasps. Conserv Biol 16:1003-1014

Klein A-M, Steffan-Dewenter I, Tscharntke T (2003a) Bee pollination and fruit set of Coffea arabica and C. canephora (Rubiaceae). Am J Bot 90:153-157

Klein A-M, Steffan-Dewenter I, Tscharntke T (2003b) Fruit set of highland coffee increases with the diversity of pollinating bees. Proc Biol Sci/R S 270:955-961

Klein A-M, Steffan-Dewenter I, Tscharntke T (2003c) Pollination of Coffea canephora in relation to local and regional agroforestry management. J Appl Ecol 40:837-845

Knoll FRN, Santos LM (2012) Orchid bee baits attracting bees of the genus Megalopta (Hymenoptera, Halictidae)in Bauru region, São Paulo, Brazil: abundance, seasonality, and the importance of odors for dim-light bees. Revista Brasileira de Entomologia $56: 481-488$

Kremen C, Ullmann KS, Thorp RW (2011) Evaluating the quality of citizen-scientist data on pollinator communities abstract. Conserv Biol 25:607-617

Kumar A, Longino JT, Colwell RK, O'Donnell S (2009) Elevational patterns of diversity and abundance of Eusocial paper wasps (Vespidae) in Costa Rica. Biotropica 41:338-346

Laroca S, Orth AI (2002) Melissocoenology: historical perspective, method of sampling, and recommendations to the "Program of conservation and sustainable use of pollinators, with emphasis on bees"(ONU). Pollinating Bees: the conservation link between Agriculture and Nature. Brasilia, Ministry of Environment, pp 217-225

Lauretta MV, Camp EV, Pine WE III, Frazer TK (2013) Catchability model selection for estimating the composition of fishes and invertebrated within a dynamic acquatic ecosystems. Can J Fish Aquat Sci 70:381-392

Leather S (2005) Insect sampling in forest ecosystems. In: Leather S, (ed) Insect sampling in forest ecosystems. Blackwell Science, London, $\mathrm{p} 620$

LeBuhn $\mathrm{G}$ et al (2003) A standardized method for monitoring Bee populations - the bee inventory (BI) plot. Accessed 16:15

LeBuhn G, Droege S, Carboni M (2007) Monitoring methods for solitary bee species using bee bowls in North America. Available from http://www.internationalpollinatorsinitiative.org/jsp/studies/studies.jsp;jsessionid=EDABA39E07204CD74B4CFCA6D 8DE651B. Accessed 31 May 2014
LeBuhn G et al (2013) Detecting insect pollinator declines on regional and global scales. Conserv Biol 27:113-120

Lemaitre AB, Pinto CF, Niemeyer HM (2014) Generalized pollination system: are floral traits adapted to different pollinators? Arthropod-Plant Interact 8:261-272

Leong JM, Thorp RW (1999) Colour-coded sampling: the pan trap colour preferences of oligolectic and nonoligolectic bees associated with a vernal pool plant. Ecol Entomol 24:329-335

Leonhardt SD, Schmitt T, Blüthgen N (2011) Tree resin composition, collection behavior and selective filters shape chemical profiles of tropical bees (Apidae: Meliponini). PLoS ONE 6:e23445

Liow L,. H, Sodhi NS, Elmqvist T (2001a) Bee diversity along a disturbance gradient in tropical lowland forests of south-east Asia. J Appl Ecol 38:180-192

Liow LH, Sodhi NS, Elmqvist T (2001b) Bee diversity along a disturbance gradient in tropical lowland forests of south-east Asia. J Appl Ecol 38:180-192

Longino JT, Colwell RK (1997) Biodiversity assessment using structured inventory: capturing the ant fauna of a tropical rain forest. Ecol Appl 7:1263-1277

Lortie CJ, Budden AE, Reid AM (2012) From birds to bees: applying video observation techniques to invertebrate pollinators. J Pollinat Ecol 6:125-128

MacKenzie DI, Nichols JD, Royle JA, Pollock KH, Bailey LL, Hines JE (2006) Occupancy estimation and modeling: inferring patterns and dynamics of species occurrence. Academic Press, Amsterdam

Malaise R (1937) A new insect trap. Entomologisk Tidskrift 58:148-160

Marston R (1965) Recent modifications in the design of the Malaise insect trap with a summary of the insects represented in collections. J Kansas Entomol Soc 38:154-162

Masner L, Goulet H (1981) A new model of flight-interception for some hymenopterous insects. Entomol News 92:199-202

Matthews RW, Matthews JR (1970) Malaise trap studies of flying insects in a New York mesic forest I Ordinal composition and seasonal abundance. New York Entomol Soc 78:52-59

Melo PN, Gimenes M, Neto AO (2009) Daily activity patterns of visits by males of four species of Eulaema (Apidae: Euglossina) to odor baits in a tropical forest fragment in Bahia. Brasil 26:204-212

Michener CD (1979) Biogeography of the Bees. Ann Mo Bot Gard $66: 277-347$

Michener CD (2007) The Bees of the WorldSecond. Johns Hopkins University Press, Baltimore

Michener CD, Cross EA, Daly HV, Rettenmeyer CW, Wille A (1955) Additional techniques for studying the behavior of wild bees. Insects Soc 2:237-246

Minckley RL (2008) Faunal composition and species richness differences of bees (Hymenoptera: Apiformes) from two north American regions. Apidologie 39:176-188

Missa O, Basset Y, Alonso A, Miller SE, Curletti G, Meyer M, Eardley C, Mansell MW, Wagner T (2008) Monitoring arthropods in a tropical landscape: relative effects of sampling methods and habitat types on trap catches. J Insect Conserv 13:103-118

Momose K, Hatada A, Yamaoka R, Inoue T (1998) Pollination biology of the genus Artocarpus. Moraceae Trop 7:165-172

Moreno CE, Halffter G (2000) Assessing the completeness of bat biodiversity inventories using species accumulation curves. J Appl Ecol 37:149-158

Myers N, Mittermeier RA, Mittermeier CG, da Fonseca GA, Kent J (2000) Biodiversity hotspots for conservation priorities. Nature 403:853-858

Nardone E (2013) The bees of algonquin park: a study of their distribution, their community guild structure, and the use of various sampling techniques in Logged and Unlogged Hardwood Stands. University of Guelph 
Nemésio A (2012) Methodological concerns and challenges in ecological studies with Orchid bees (Hymenoptera: Apidae: Euglossina). Biosci J 28:118-135

Nemésio A, Morato EF (2006) The orchid-bee fauna (Hymenoptera: Apidae) of Acre state (northwestern Brazil) and a re-evaluation of euglossine bait-trapping. Lundiana 7:59-64

Nemésio A, Silveira FA (2006) Edge effects on the orchid-bee fauna (Hymenoptera: Apidae) at a large remnant of Atlantic Rain Forest in southeastern Brazil. Neotrop Entomol 35:313-323

Nemésio A, Silva DP, Nabout JC, Varela S (2016) Effects of climate change and habitat loss on a forest-dependent bee species in a tropical fragmented landscape. Insect Conserv Divers 9:149-160

New TR (1998) Invertebrate surveys for conservation. Oxford University Press, Oxford

Ngo HT, Gibbs J, Griswold T, Packer L (2013) Evaluating bee (Hymenoptera: Apoidea) diversity using Malaise traps in coffee landscapes of Costa Rica. Can Entomol 145:435-453

Nichols JD, Williams KB (2006) Monitoring for conservation. Trends Ecol Evol 21:668-673

Nichols JD, Hines JE, MacKenzie DI, Seamans ME, Gutierrez RJ (2007) Occupancy estimation and modeling with multiple states and state uncertainity. Ecology 88:1395-1400

Nieh JC, Contrera FAL, Ramírez S, Imperatriz-Fonseca VL (2003a) Variation in the ability to communicate three-dimensional resource location by stingless bees from different habitats. Anim Behav 66:1129-1139

Nieh JC, Ramirez S, Nogueira-Neto P (2003b) Multi-source odormarking of food by a stingless bee, Melipona mandacaia. Behav Ecol Sociobiol 54:578-586

Noyes JS (1989) The diversity of Hymenoptera in the tropics with special reference to Parasitica in Sulawesi. Ecol Entomol 14:197-207

Pacifici K, Zipkin EF, Collazo JA, Irizarry JI, DeWan A (2014) Guidelines for a priori grouping of species in hierarchical community models. Ecol Evol 4:877-888

Pacifici JK, Reich BJ, Miller DAW, Gardner B, Stauffer G, Singh S, McKerrow A, Collazo JA (2017) Integrating multiple data sources in species distribution modeling: a framework for data fusion. Ecology 98:840-850

Packer L (2013) Patagonicola: a new genus of xeromelissine bee from Argentina (Hymenoptera: Apoidea: Colletidae). Can Entomol $3: 1-23$

Pannure A, Chandrashekara K (2013) Seasonal patterns in the diversity of Apis and non-Apis bees in an agro-ecosystem: a case study from eastern dry zone of Karnataka. Curr Biotica 6:432-444

Pearson DL, Dressler RL (2009) Two-year study of male orchid bee (Hymenoptera: Apidae: Euglossini) attraction to chemical baits in lowland south-eastern Perú. J Trop Ecol 1:37

Peck SB, Davis AE (1980) Collecting small beetles with large-area "Window" traps. Coleopter Bull 34:237-239

Pinheiro F, Diniz IR, Coehlo D, Bandeira MPS (2002) Seasonal pattern of insect abundance in the Brazilian cerrado. Austral Ecol 27:132-136

Popic TJ, Davila YC, Wardle GM (2013) Evaluation of common methods for sampling invertebrate pollinator assemblages: net sampling out-perform pan traps. PLoS ONE 8:e66665

Potts SG, Imperatriz-fonseca V, Ngo HT, Aizen MA, Biesmeijer JC, Breeze TD (2016) Safeguarding pollinators and their values to human well-being. Nat Publ Group 540:220-229

Price M, Waser N, Irwin R (2005) Temporal and spatial variation in pollination of a montane herb: a seven-year study. Ecology 86:2106-2116

Rader R, Reilly J, Bartomeus I, Winfree R (2013) Native bees buffer the negative impact of climate warming on honey bee pollination of watermelon crops. Glob Change Biol 19:3103-3110
Ramírez SR, Eltz T, Fritzsch F, Pemberton R, Pringle EG, Tsutsui ND (2010) Intraspecific geographic variation of fragrances acquired by orchid bees in native and introduced populations. J Chem Ecol 36:873-884

Renner SS, Feil JP (1993) Pollinators of tropical dioecious angiosperms. Am J Bot 80:1100-1107

Reyes-Novelo E, Méléndez-Ramírez V, Ayala R, Delfín-González H (2009) Bee Faunas (Hymenoptera: Apoidea) of six natural protected areas in Yucatan. Mex Entomol News 120:530-544

Ricketts T (2004) Tropical forest fragments enhance pollinator activity in nearby coffee crops. Conserv Biol 18:1-10

Rocha-Filho LC, Krug C, Silva CI, Garófalo CA (2012) Floral resources used by Euglossini bees (Hymenoptera: Apidae) in coastal ecosystems of the Atlantic Forest. Psyche 2012:1-13

Rodríguez-Oseguera AG, Casas A, Herrerías-Diego Y, Pérez-Negrón E (2013) Effect of habitat disturbance on pollination biology of the columnar cactus Stenocereus quevedonis at landscape-level in central Mexico. Plant Biol 15:573-582

Romney VE (1945) The effect of physicai factors uponcatch of' the beet leafhopper (Eutettix tenellus Bak.) by a cylinder and two sweep-net methods. Ecology 26:135-147

Roubik DW (2001) Ups and downs in pollinator populations: when is there a decline? Conserv Ecol 5:2

Roubik DW, Aluja M (1983) Flight ranges of Melipona and Trigona in tropical forest. J Kansas Entomol Soc 56:217-222

Roulston TH, Smith SA, Brewster AL (2007) A comparison of Pan Trap and intensive net sampling techniques for documenting a bee (Hymenoptera: Apiformes) fauna. J Kansas Entomol Soc 80:179-181

Sakagami SF, Laroca S, Moure JS. 1967. Wild bee biocenotics in São José dos Pinhais (Pr), south Brazil: preliminary report. J Fac Sci Hokkaido Univ Ser. VI Zool 16:253-291

Samnegård U, Persson AS, Smith HG (2011) Gardens benefit bees and enhance pollination in intensively managed farmland. Biol Conserv 144:2602-2606

Schauff ME (1986) Collecting and preserving insects and mites: techniques and tools. In: Schauff ME (ed) Systematic Entomology Laboratory, USDA, Washington, D.C.

Schüepp C, Rittiner S, Entling MH (2012) High bee and wasp diversity in a heterogeneous tropical farming system compared to protected forest. PLoS ONE 7:e52109

Sepsenwol S (2015) The zip net: an insect sweep net with removable capture pouch for serial collecting. Am Entomol 60:207-209

Smith-Pardo AH (1999) Evaluación de cinco métodos de muestreo para abejas en dos estados sucesionales del area de influencia del embalse porce II (antioquia). Revista Facultad Nacional de Agronomía Medellín 52:435-450

Smith-Pardo A, Gonzalez VH (2007) Bee diversity (Hymenoptera: Apoidea) in a tropical rainforest succession. Acta biológica colombiana 12:43-55

Solar RR de (2015) How pervasive is biotic homogenization in humanmodified tropical forest landscapes? Ecol Lett 18:1108-1118

Southwood TRE., Henderson PA (2000) Ecological methods, 3rd edn. Blackwell Science, Oxford

Souza L, De, Campos MJDO (2008) Composition and diversity of bees (Hymenoptera) attracted by Moericke traps in an agricultural area in Rio Claro, state of São Paulo, Brasil. Iheringia Série Zoologia 98:236-243

Sydney NV, Gonçalves RB (2015) Is the capture success of orchid bees (Hymenoptera, Apoidea) influenced by different baited trap designs? A case study from southern Brazil. Revista Brasileira de Entomologia 59:32-36

Tangmitcharoen S, Takaso T, Siripatanadilox S, Tasen W, Owens JN (2006) Insect biodiversity in flowering teak (Tectona grandis L.f.) canopies: Comparison of wild and plantation stands. For Ecol Manage 222:99-107 
Thomas DB (2008) Nontoxic antifreeze for insect traps. Entomol News 119:361-365

Tonhasca A Jr, Albuquerque GS, Blackmer JL (2003) Dispersal of euglossine bees between fragments of the Brazilian Atlantic Forest. J Trop Ecol 19:99-102

Townes H (1972) A light-weight malaise trap. Entomol News 83:239-247

Tuell JK, Isaacs R (2009) Elevated pan traps to monitor bees in flowering crop canopies. Entomol Exp Appl 131:93-98

Ugland KI, Gray JS, Ellingsen KE (2003) The species-accumulation curve and estimation of species richness. J Anim Ecol 72:888-897

Van Achterberg K (2009) Can Townes type Malaise traps be improved? Some recent developments. Entomologische Berichten 69:129-135

Vardal H, Taeger A (2011) The life of René Malaise: from the wild east to a sunken island. Zootaxa 3127:38-52

Vergara CH, Ayala R (2002) Diversity, phenology and biogeography of the bees (Hymenoptera: Apoidea) of Zapotitlan de las Salinas, Puebla, Mexico. J Kansas Entomol Soc 75:16-30
Vergara CH, Badano EI (2009) Pollinator diversity increases fruit production in Mexican coffee plantations: the importance of rustic management systems. Agric Ecosyst Environ 129:117-123

Westphal C et al (2008) Measuring bee diversity in different European habitats and biogeographical regions. Ecol Monogr 78:653-671

Williams BK, Nichols JD, Conroy MJ (2002) Analysis and management of animal populations: modeling, estimation, and decision making. Academic Press, New York

Willott SJ (2001) Species accumulation curves and the measure of sampling effort. J Appl Ecol 38:484-486

Wilson JS, Griswold T, Messinger OJ (2008) Sampling bee communities (Hymenoptera: Apiformes) in a desert landscape: are pan traps sufficient? J Kansas Entomol Soc 81:288-300

Yackulic CB, Nichols JD, Reid J, Der R (2015) To predict the niche, model colonization and extinction. Ecology 96:16-23

Yi Z, Jinchao F, Dayuan X, Weiguo S, Axmacher JC (2012) A Comparison of terrestrial arthropod sampling methods. J Resour Ecol 3:174-182

Zale AV, Parrish DL, Sutton TM (eds) (2013) Fisheries techniques, 3rd edn. American Fisheries Society, Bethesda 